\title{
Effects of aiming lines and visual function on the golf putting alignment
}

\author{
You-Jin Kim ${ }^{1,2}$, Young-Gap Jin ${ }^{3}$, Bon-Yeop Koo ${ }^{4}$, Jung-Un Jang ${ }^{5}$ and Ki-Choong $\mathrm{Mah}^{5}$ \\ ${ }^{1}$ Ketchum University's Southern California College of Optometry, CA, USA \\ ${ }^{2}$ Department of Optometry, Graduate School of Public Health, Eulji University, Daejeon, Korea \\ ${ }^{3}$ Korean Optometric Association, Vice Chairman of Ethics, Seoul, Korea \\ ${ }^{4}$ Department of Optometry, Shinsung University, Dangjin, Korea \\ ${ }^{5}$ Department of Optometry, Eulji University, Seongnam, Korea
}

\begin{abstract}
Background: In golf, a player hits a ball with a club, aiming to transfer the ball successively into a series of hole cups in a course consisting of 18 (or fewer) holes. This study aimed to compare the impact of visual function and the presence and number of aiming lines on golf putting alignment between beginner and expert golfers. Methods: In this prospective comparative study, 43 participants with a mean \pm standard deviation (SD) of corrected distance binocular visual acuity of $-0.07 \pm 0.74$ logarithm of the minimum angle of resolution, who knew their average golf scores, were divided into beginner and expert golfers. Six visual function tests were conducted to assess heterotropia, dominant eye, verification of current spectacles, static visual acuity, stereopsis, and fixation disparity. At the putting distances of $1.5 \mathrm{~m}$ and $3 \mathrm{~m}$, alignment errors were measured five times each, using golf balls with 1 and 3 aiming line(s) and putters with 1 and 3 aiming line(s).

Results: The mean \pm SD of age was $48.33 \pm 10.07$ years for study participants overall. The accuracy of ball alignment was not affected by the career or number of aiming lines, but the putter alignment was higher for the 3 -lines putter than for the 1 -line putter $(P<0.05)$. When the number and shape of the aiming line were the same for both the ball and putter, the aiming accuracy was found to be higher. In both stereopsis and fixation disparity, the combination of putting distance and a 3-lines ball showed negative values; all other combinations showed positive values, but no statistically significant correlation was detected (all $P>0.05$ ). Conclusions: The accuracy of golf ball alignment did not depend on the number of aiming lines and the golfer's career. However, the predicted putting success rate and subjective satisfaction were increased when three-line golf balls and putters were used, as compared to when one-line golf balls and putters were used.
\end{abstract}

\section{KEYWORDS}

aiming line, putting, alignment, dominant eye, sport vision, golfer, golf ball, putter

\section{INTRODUCTION}

In golf, a player hits a ball with a club, aiming to transfer the ball successively into a series of hole cups in a course consisting of 18 (or fewer) holes. In this sport, the person who requires fewer hits to achieve this goal wins the game. An 18-hole game is called a one-round game. In the one-round game, putting takes up about $43 \%$ of all strokes. Many golfers find it difficult to perform the putting process [1]. When putting is conducted without

Correspondence: Ki-Choong Mah, Professor, Department of Optometry, Eulji University, Seongnam, Korea. Email: kcmah@eulji.ac.kr. ORCID iD: https:// orcid.org/0000-0001-7762-2615

How to cite this article: Kim YJ, Jin YG, Koo BY, Jang JU, Mah KC. Effects of aiming lines and visual function on the golf putting alignment. Med Hypothesis Discov Innov Optom.2021 Spring; 2(1): 41-49. DOI: https://doi.org/10.51329/mehdioptometry124

Received: 26 March 2021 Accepted: 02 May 2021

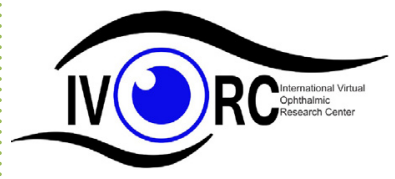

Copyright (C) Author(s). This is an open-access article distributed under the terms of the Creative Commons Attribution-NonCommercial 4.0 International License (http://creativecommons.org/licenses/by-nc/4.0/) which permits copy and redistribute the material just in noncommercial usages, provided the original work is properly cited. (c) (i) \& 
alignment of the putter head, the direction of movement of the golf ball is similar to the angle at which the putter head was bent. The error of the putter head alignment angle has a significant impact on the direction of movement of the golf ball $[2,3]$. By applying this error range to a trigonometric function, at distances of 1.5 and $3 \mathrm{~m}$, the putter head alignment error should be within $2.06^{\circ}$ (or $123.7 \mathrm{arcmin}$ ), and $1.03^{\circ}(61.9 \mathrm{arcmin})$, respectively, to ensure successful putting (Figure 1).

Various products have been launched to facilitate precise putting. These devices help to align the putter head by adding aiming lines onto the golf ball and putter [4]. However, no clear analysis of the impact of the presence and number of aiming lines on the golf ball and putter head alignment in actual putting has been reported.

In golf, focus flexibility and stereoacuity are needed to judge distance and position. Visual acuity is also important for clear fixation of the target, and good vernier acuity is required for the correct alignment to the hole cup, using the auxiliary line in putting $[5,6]$.

Two previous studies $[7,8]$ showed that, in golf putting, visual acuity and visual exploration processes may affect the accuracy of putting by affecting athletic performance. Woo et al. [9] reported that, in expert golfers as the stroke was well-fixed due to long-term practice, looking at the hole or the ball had no effect on putting at all. On the other hand, in beginner golfers, the stroke differed according to the form of visual acuity. Dalton [10] noted that the dominant eye and dominant hand did not have a close relationship with the golfer's skill level, but found that the dominant eye could be an important factor in putting success. Won [11] found that fixation disparity in the visual functions required for putting revealed a correlation between alignment ability and putting error. Bulson et al. [12] investigated the correlation between golf putting ability and visual acuity. However, to date, there has been no attempt to analyze the effect of aiming lines on putting ability, and it is necessary to analyze the visual function.

In this study, we aimed to investigate the impact of visual function and the presence and number of aiming lines on the alignment state in putting between expert and beginner golfers, defined by their average score in virtual putting space.

\section{METHODS}

This was a comparative prospective study that was approved by the institutional review board of Eulji University, Korea (Approval No.: EU20-07). Subjects consented to participation after receiving a sufficient explanation of the purpose and details of the examination.

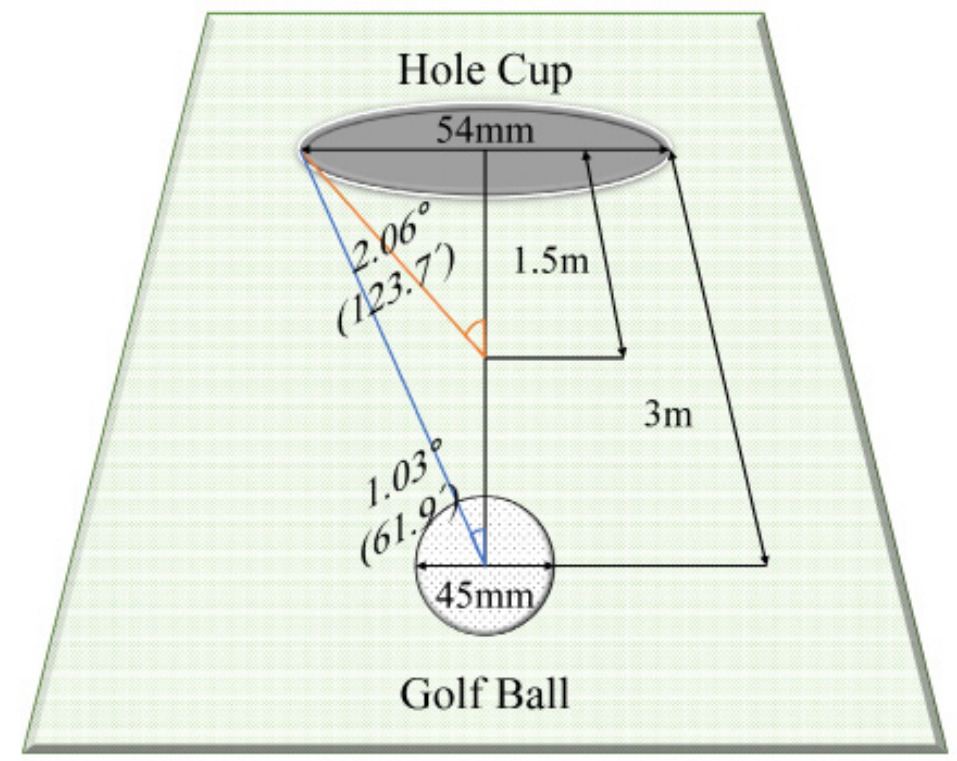

Figure 1. Differences in the hole-in angles in accordance with the increase in putting distance. Note: at putting distances of 1.5 and 3 meters $(\mathrm{m})$, the putter head alignment error should be within $2.06^{\circ}\left(123.7 \mathrm{arcmin}\left[{ }^{\prime}\right]\right)$, and $1.03^{\circ}\left(61.9^{\prime}\right)$, respectively, to ensure successful putting.

Participants were included if they knew their mean scores in the field for the recent year, did not have strabismus 
or amblyopia, had a distance binocular visual acuity better than 0.1 logarithm of the minimum angle of resolution $(\log M A R)$, and consented to participate.

The sample size of the study was calculated with the $G^{*}$ power $[13,14]$ Ver. 3.1.9.7 for Windows (HeinrichHeine-Universität Düsseldorf, Germany). The required sample size for $90 \%$ power, $\alpha=0.05$ type I error, and $d$ $=0.50$ effect size was 36 , with 18 participants in each group. However, to protect the study from potential loss to follow-up because of the long follow-up period, $25 \%$ more participants were scheduled to be enrolled in each group. The average score in the field, using a generic career, over a period of 1 year was calculated for all subjects and the following formula was applied: G.C. = A.S. - 72, where G.C., A.S., and 72 refer to the generic career, average score, and default number of strokes in a 1-round game (18 holes), respectively [15]. For analysis according to golf career (mean score 90 strokes), the golfers were divided into beginner (mean score $\leq 90$ strokes) and expert (mean score $>90$ strokes) groups. Forty-three right-handed golfers with a mean \pm standard deviation (SD) age of $48.33 \pm 10.07$ years were selected.

The two golf balls for ball measurement used was an official product registered under U.S. patent 6872150 [16]. To create a ball with one aiming line, a single aiming line was added to the center in the method golfers generally use. To create a ball with three aiming lines, the ERC Soft Triple Track (Callaway Golf Company, Carlsbad, CA, USA) was reproduced. A measurement laser was inserted into the center of all the golf balls to measure the alignment error (Figure 2). As a putter with one aiming line, the Stroke Lab 19 \#3 (Callaway Golf Company) was used, and for that with three aiming lines, the Triple Track Marxman (Callaway Golf Company) was used. The mirror was attached perpendicular to the face side of the toe of the putter head (the part where the ball and putter meet) (Figure 3) $[17,18]$. An Optics System 3 (Altay Scientific Co., Rome, Italy) was used to measure the error angle of the putter alignment.
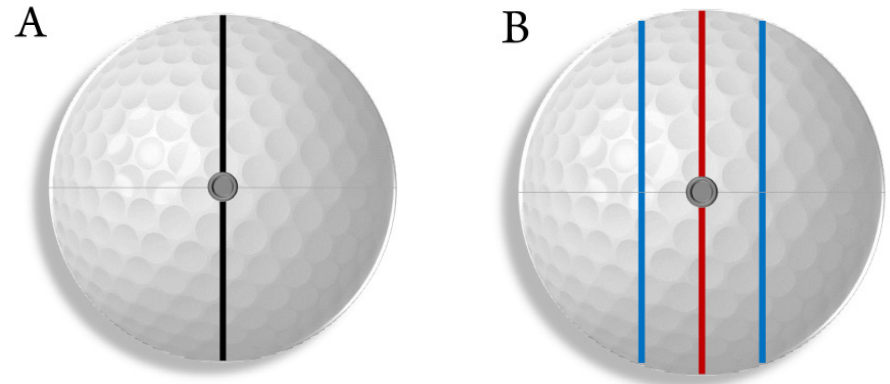

Figure 2. The golf balls used in this study: (A) golf ball with one aiming line and (B) with three aiming lines.

\section{Hole Cup}
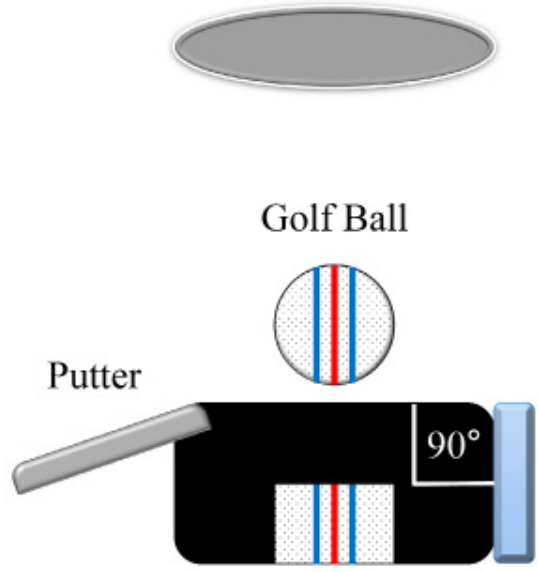

Mirror

Figure 3. The mirror-attached putter used in this study. The mirror was attached perpendicular to the face side of the toe of the putter head (the part where the ball and putter meet). 
An artificial grass board, $1 \mathrm{~m}$ long and $4 \mathrm{~m}$ wide, was installed to conduct putting in an environment similar to the reality, and the measuring device was placed so that it would not disturb putting. To measure golf ball alignment, the hole cup (target hole) was placed at two lengths: $1.5 \mathrm{~m}$ and $3 \mathrm{~m}$, and the measurement scale and recording camera were placed behind the hole cup (Figure 4A). To measure putter alignment, the hole cup was placed at $1.5 \mathrm{~m}$, and the measurement scale and recording camera were placed at $2 \mathrm{~m}$, attached the mirror to the putter face, such that they could maintain the same angle to each other (Figure 4B). All alignment errors were measured five times to calculate the mean value, and were made randomly to exclude the learning effect, and the results were disclosed after the completion of the experiment.

Six visual function tests were conducted as preliminary tests to assess heterotropia (using a cover test) [19], dominant eye [20], verification of current spectacles (with a Topcon LM-S1 lensometer, Topcon Corporation, Tokyo, Japan), static visual acuity (monocular and binocular uncorrected or corrected vision at $3 \mathrm{~m}$, using a Logarithmic Visual Acuity Chart, Precision Vision Inc., LaSalle, IL, USA), as well as both near and distance stereoacuity and fixation disparity.

Hole cups were placed at $1.5 \mathrm{~m}$ and $3 \mathrm{~m}$ linear distance from the golf ball, set randomly, and the alignment state was measured using a golf ball in which the laser was inserted. The golf ball was positioned in front of the putter. Three types of golf balls ( 0,1 , and 3 aiming line) and two types of putter (one and three aiming lines) were used. For golf balls with aiming line(s), the measurer first aligned the aiming line and the hole cup, and then the subjects aligned them once after checking the alignment state set by the measurer.

The satisfaction of participants was investigated according to the presence of aiming lines through a questionnaire newly developed for the current study. The questionnaire was composed of five statements to
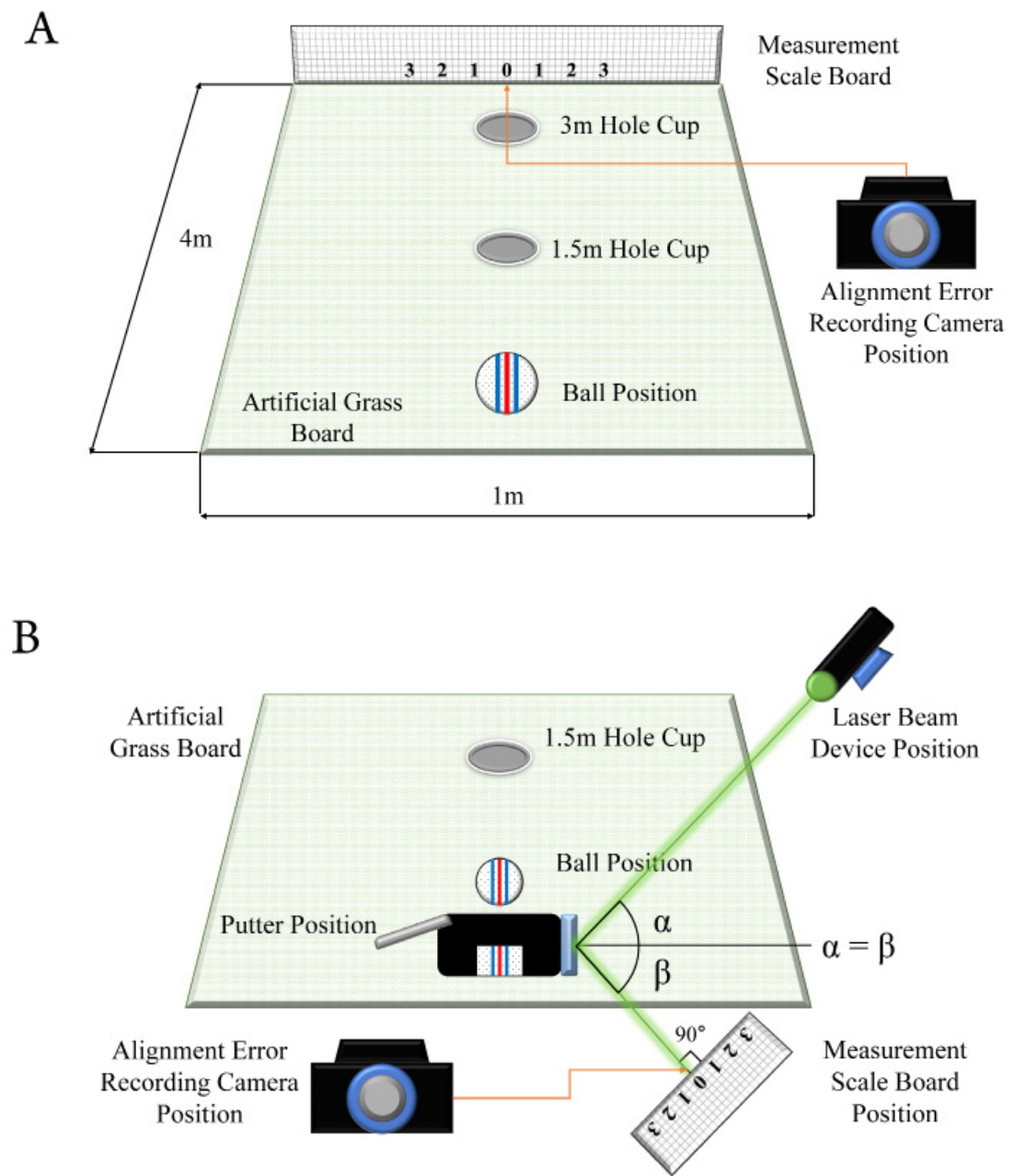

Figure 4. Schematic diagrams of the experimental equipment. Alignment measurement for $(A)$ the golf balls and $(B)$ the putter. 
which the subject responded on a 5-point scale $(-2,-1,0,+1$, and +2 for strongly agree, somewhat agree, neither agree nor disagree, somewhat disagree, and strongly disagree, respectively). We developed the following five statements to assess satisfaction with the golf ball and putter alignment: 1) a ball without a line was helpful for aiming, 2) a ball with one line was helpful for aiming, 3) a ball with three lines was helpful for aiming, 4) one short line drawn on the putter facilitated the aim, and 5) three lines drawn on the putter facilitated the aim.

For statistical analysis, SPSS Statistics for Windows, version 18.0, (IBM SPSS Inc., Chicago, IL, USA) and OriginPro 8.1 (OriginLab, Northampton, MA, USA) were used. Error scores were measured in degrees from the aim of each ball and the putter's target: constant error (aiming bias), absolute error (aiming accuracy), and variable error (aiming consistency). An independent $t$-test was used to compare the means of the two subject groups. A paired t-test was performed to compare the mean difference between the aiming aids and the number of successful alignments. Correlation analysis was performed to determine the correlation between visual function and alignment error. A repeated-measures analysis of variance test was performed to compare the misalignment errors of all types of balls. For all statistical analyses, the significance probability was $\leq 0.05$.

\section{RESULTS}

Table 1 shows the baseline characteristics and visual function measurements of the study participants.

The relationship between the career (beginner versus expert golfers), and alignment error was investigated by comparing the golf ball alignment error according to the career and the putter alignment error between the two groups. There were no significant differences in absolute error or aiming accuracy between the two groups according to the putting distance and type of putter $(P>0.05)$ (Table 2). However, the SD was decreased more in the beginner group at both lengths when switching from a one-line putter to a three-line putter. The mean variable error or aiming consistency at both lengths was significantly lower in beginners when using a one-line putter $(P<$ $0.05)$. There was a significant difference in mean variable error or aiming consistency between the beginner and expert golfer groups when using the three-line putter with the three-line golf ball $(P<0.05)$ (Table 2$)$.

The relationship between aiming lines and alignment errors was investigated by assessing the alignment error and predicted putting success rate for the different golf balls, and the alignment error of the putter and predicted putting success rate according to the aiming line of the golf balls and the putters (Table 3). Additionally, the final alignment error of the golf balls and putters were determined according to the combinations of aiming lines (Table 4).

Alignment errors for the three-line golf ball were less than those for the one-line golf ball; however, there was no statistically significant difference according to the type of golf ball $(P>0.05)$ (Table 3$)$. At $1.5 \mathrm{~m}$, the predicted putting success rate of the three-line golf ball was significantly increased compared to that of the one-line golf ball $(P<0.05)$ (Table 3$)$. The alignment error of the three-line putter was significantly decreased compared to that of the one-line putter, for both the ball without a line and for the 3 -line ball $(P<0.05)$. The predicted putting success rate with the three-line putter was significantly increased as compared to that of the one-line putter, when using the three-line ball $(P<0.05)$ (Table 3$)$. The final alignment errors were analyzed by combining the alignment errors of the golf balls and putters. An alignment error to the right was marked as a $(+)$ value, and an alignment error to the left was marked as a (-) value. The alignment error was significantly decreased for the combination of both putters with a three-line golf ball as compared to that with a one-line golf ball (Table 4).

Table 1. Baseline characteristics of the study participants

\begin{tabular}{|c|c|c|}
\hline \multicolumn{3}{|l|}{ Variable } \\
\hline \multicolumn{2}{|l|}{ Age (y), Mean \pm SD (Range) } & $48.33 \pm 10.07(21$ to 65$)$ \\
\hline \multirow{2}{*}{ Binocular Corrected Visual Acuity (logMAR), Mean \pm SD (Range) } & Distance & $-0.07 \pm 0.74(-0.29$ to 0.03$)$ \\
\hline & Near & $0.05 \pm 0.62(-0.10$ to 0.32$)$ \\
\hline \multirow{2}{*}{ Stereopsis (Second of Arc), Mean \pm SD (Range) } & Distance & $7.5 \pm 6.64(0.99$ to 29.41$)$ \\
\hline & Near & $44.2 \pm 9.32(40$ to 80$)$ \\
\hline \multirow{2}{*}{ Fixation Disparity (Minute of Arc), Mean \pm SD (Range) } & Distance & $0.02 \pm 0.05(-0.06$ to 0.17$)$ \\
\hline & Near & $2.57 \pm 3.46(-4.30$ to 9.80$)$ \\
\hline Sex, n $(\%)$ & Male/Female & $27(62.8) / 16(37.2)$ \\
\hline Dominant Eye, n (\%) & $\mathrm{OD} / \mathrm{OS}$ & $33(76.7) / 10(23.3)$ \\
\hline \multirow{2}{*}{ Group, n (\%) } & Beginner Golfers & $20(46.5)$ \\
\hline & Expert Golfers & $23(53.5)$ \\
\hline
\end{tabular}

Abbreviations: y, years; SD, standard deviations; logMAR, logarithm of the minimum angle of resolution; n: number; \%, percentage; OD, right eye; OS, left eye. 
Table 2. Comparison of aiming errors of the golf balls and putters between two groups

\begin{tabular}{|c|c|c|c|c|c|}
\hline \multirow{3}{*}{\multicolumn{2}{|c|}{$\begin{array}{l}\text { Variable } \\
\text { Length (m) } \\
\text { Type of Putter }\end{array}$}} & \multicolumn{4}{|c|}{ Aiming Error $($ Mean \pm SD $)$} \\
\hline & & \multicolumn{2}{|c|}{$1.5 \mathrm{~m}$} & \multicolumn{2}{|c|}{$3 \mathrm{~m}$} \\
\hline & & One-Line Putter & Three-Line Putter & One-Line Putter & Three-Line Putter \\
\hline \multirow{3}{*}{$\begin{array}{l}\text { Aiming Accuracy } \\
\left(\text { Absolute error, in }{ }^{\circ}\right)\end{array}$} & Beginners & $1.11 \pm 0.78$ & $0.94 \pm 0.54$ & $1.13 \pm 0.81$ & $0.93 \pm 0.52$ \\
\hline & Experts & $1.03 \pm 0.68$ & $0.98 \pm 0.53$ & $1.04 \pm 0.62$ & $0.89 \pm 0.58$ \\
\hline & $P$-value & 0.715 & 0.802 & 0.662 & 0.854 \\
\hline \multirow{3}{*}{$\begin{array}{l}\text { Aiming Consistency } \\
\left(\text { Variable error, in }^{\circ}\right)\end{array}$} & Beginners & $0.43 \pm 0.19$ & $0.51 \pm 0.21$ & $0.50 \pm 0.31$ & $0.51 \pm 0.37$ \\
\hline & Experts & $0.68 \pm 0.39$ & $0.69 \pm 0.38$ & $0.75 \pm 0.36$ & $0.58 \pm 0.43$ \\
\hline & $P$-value & 0.009 & 0.067 & 0.020 & 0.561 \\
\hline \multicolumn{3}{|l|}{ Type of Ball } & Ball without line & One-Line Ball & Three-Line Ball \\
\hline \multirow{6}{*}{$\begin{array}{l}\text { Aiming Accuracy } \\
\left(\text { Absolute error, in }{ }^{\circ}\right)\end{array}$} & \multirow{3}{*}{ One-Line Putter } & Beginners & $2.06 \pm 1.24$ & $1.91 \pm 1.29$ & $1.98 \pm 1.33$ \\
\hline & & Experts & $2.73 \pm 1.5$ & $1.73 \pm 1.08$ & $2.82 \pm 1.38$ \\
\hline & & P-value & 0.133 & 0.618 & 0.050 \\
\hline & \multirow{3}{*}{ Three-Line Putter } & Beginners & $1.52 \pm 1.06$ & $1.83 \pm 1.23$ & $1.75 \pm 1.57$ \\
\hline & & Experts & $1.62 \pm 1.0$ & $1.89 \pm 0.93$ & $1.43 \pm 0.75$ \\
\hline & & $P$-value & 0.777 & 0.863 & 0.384 \\
\hline \multirow{6}{*}{$\begin{array}{l}\text { Aiming Consistency } \\
\left(\text { Variable error, in }^{\circ}\right)\end{array}$} & \multirow{3}{*}{ One-Line Putter } & Beginners & $0.78 \pm 0.33$ & $0.61 \pm 0.24$ & $0.63 \pm 0.26$ \\
\hline & & Experts & $0.96 \pm 0.49$ & $0.77 \pm 0.28$ & $0.87 \pm 0.52$ \\
\hline & & $P$-value & 0.171 & 0.069 & 0.067 \\
\hline & \multirow{3}{*}{ Three-Line Putter } & Beginners & $0.74 \pm 0.38$ & $0.68 \pm 0.30$ & $0.63 \pm 0.24$ \\
\hline & & Experts & $1.00 \pm 0.71$ & $0.79 \pm 0.46$ & $0.92 \pm 0.56$ \\
\hline & & $P$-value & 0.158 & 0.342 & 0.029 \\
\hline
\end{tabular}

Abbreviations: SD, standard deviation; beginners, beginner golfers; experts, expert golfers; $P$-value $<0.05$ is shown in bold.

Table 3. Comparison of aiming error (absolute error) and predicted putting success rate when using golf balls and putters with one or three aiming lines based on both beginner and expert groups

\begin{tabular}{|c|c|c|c|}
\hline \multirow{2}{*}{$\begin{array}{l}\text { Variable } \\
\text { Length (m) }\end{array}$} & \multicolumn{2}{|c|}{ Aiming Error $($ Mean \pm SD $)$} & \multirow[b]{2}{*}{3} \\
\hline & & 1.5 & \\
\hline \multirow{3}{*}{ Aiming Accuracy (Absolute error, in $\left.{ }^{\circ}\right)$} & One-Line Ball & $1.07 \pm 0.19$ & $1.08 \pm 0.71$ \\
\hline & Three-Line Ball & $0.96 \pm 0.53$ & $0.91 \pm 0.54$ \\
\hline & $P$-value & 0.186 & 0.094 \\
\hline \multirow{4}{*}{ Predicted Putting Success Rate (\%) } & One-Line Ball & $82.79 \pm 31.04$ & $58.60 \pm 35.56$ \\
\hline & Three-Line ball & $93.49 \pm 17.30$ & $64.19 \pm 36.66$ \\
\hline & Difference & $10.70 \pm 25.20$ & $5.58 \pm 37.37$ \\
\hline & $P$-value & 0.008 & 0.333 \\
\hline \multicolumn{2}{|l|}{ Type of Balls } & One-Line Ball & Three-Line Ball \\
\hline \multirow{3}{*}{ Aiming Accuracy (Absolute error, in ${ }^{\circ}$ ) } & One-Line Putter & $1.81 \pm 1.71$ & $2.43 \pm 1.41$ \\
\hline & Three-Line Putter & $1.86 \pm 1.06$ & $1.57 \pm 1.20$ \\
\hline & $P$-value & 0.858 & 0.002 \\
\hline \multirow{4}{*}{ Predicted Putting Success Rate (\%) } & One- Line Putter & $64.19 \pm 39.89$ & $45.12 \pm 43.23$ \\
\hline & Three-Line Putter & $59.07 \pm 38.04$ & $72.56 \pm 36.52$ \\
\hline & Difference & $5.12 \pm 57.25$ & $27.44 \pm 54.51$ \\
\hline & $P$-value & 0.561 & 0.002 \\
\hline
\end{tabular}

Abbreviations: \%, percentage; SD, standard deviation. $P$-value $<0.05$ is shown in bold. 
Table 4. Comparison of aiming error with various golf ball and putter combinations

\begin{tabular}{|c|c|c|c|c|}
\hline \multirow{2}{*}{$\begin{array}{l}\text { Variable } \\
\text { Type of Putters }\end{array}$} & & \multicolumn{2}{|c|}{ Aiming Error $($ Mean \pm SD $)$} & \multirow{2}{*}{$P$-value } \\
\hline & & One-Line Putter & Three-Line Putter & \\
\hline \multirow{3}{*}{ Only Ball Aiming } & Only One-Line Ball & \multicolumn{2}{|c|}{$-0.48 \pm 1.15$} & \\
\hline & Only Three-Line Ball & \multicolumn{2}{|c|}{$-0.60 \pm 0.85$} & \\
\hline & $P$-value & \multicolumn{2}{|c|}{0.285} & \\
\hline \multirow{3}{*}{ Only Putter Aiming } & Only Putter & $+1.01 \pm 1.88$ & $-0.53 \pm 2.06$ & $<0.001$ \\
\hline & Only Putter & $+1.97 \pm 1.98$ & $+0.19 \pm 1.92$ & $<0.001$ \\
\hline & $P$-value & 0.003 & 0.014 & \\
\hline \multirow{3}{*}{$\begin{array}{l}\text { Combination of Ball and } \\
\text { Putter Aiming }\end{array}$} & One-Line Ball with Putter & $+0.52 \pm 2.54$ & $-1.02 \pm 2.42$ & $<0.001$ \\
\hline & Three-Line Ball with Putter & $+1.37 \pm 2.34$ & $-0.41 \pm 2.12$ & $<0.001$ \\
\hline & $P$-value & 0.008 & 0.034 & \\
\hline
\end{tabular}

Abbreviations: SD, standard deviation. Note: (+), (-): Deviations in the right and left directions, respectively. $P$-value $<0.05$ is shown in bold.

Table 5. Comparison of aiming error (constant error) of balls and putters according to eye dominance

\begin{tabular}{|c|c|c|c|c|c|}
\hline \multirow{3}{*}{$\begin{array}{l}\text { Putting Distance (m) } \\
\text { Type of Ball }\end{array}$} & & \multicolumn{4}{|c|}{$\operatorname{Aiming}$ Error $($ Mean \pm SD $)$} \\
\hline & & \multicolumn{2}{|c|}{1.5} & \multicolumn{2}{|c|}{3} \\
\hline & & One-Line Ball & Three-Line Ball & One-Line Ball & Three-Line Ball \\
\hline & OD $(n=33)$ & $-0.34 \pm 1.17$ & $-0.49 \pm 0.87$ & $-0.42 \pm 1.20$ & $-0.47 \pm 0.86$ \\
\hline & OS $(n=10)$ & $-0.96 \pm 0.99$ & $-0.96 \pm 0.69$ & $-0.76 \pm 0.79$ & $-0.73 \pm 0.62$ \\
\hline & $P$-value & 0.139 & 0.127 & 0.419 & 0.384 \\
\hline \multicolumn{2}{|l|}{ Type of Ball } & \multicolumn{2}{|c|}{ Ball Without Line } & One-Line Ball & Three-Line Ball \\
\hline \multirow{3}{*}{ One-Line Putter } & OD $(n=33)$ & $+2.02 \pm 2.27$ & & $+1.06 \pm 1.87$ & $+2.30 \pm 1.99$ \\
\hline & OS $(n=10)$ & $+1.37 \pm 1.28$ & & $+0.82 \pm 2.00$ & $+0.88 \pm 1.56$ \\
\hline & $P$-value & & & 0.726 & 0.045 \\
\hline \multirow{3}{*}{ Three-Line Putter } & OD $(n=33)$ & $+0.14 \pm 1.81$ & & $-0.26 \pm 2.00$ & $+0.59 \pm 1.81$ \\
\hline & OS $(n=10)$ & $-0.28 \pm 1.76$ & & $-1.45 \pm 2.34$ & $-0.83 \pm 2.08$ \\
\hline & $P$-value & & & 0.110 & 0.054 \\
\hline
\end{tabular}

Abbreviations: m, meter; SD, standard deviation; OD, dominant right eye; OS, dominant left eye; n, number. Note: (+), (-): right and left direction deviations, respectively. $P$-value $<0.05$ is shown in bold.

Table 6. Comparison of aiming error (constant error) of the golf ball and putter combinations with eye-dominance

\begin{tabular}{l|l|l|l|l|}
$\begin{array}{l}\text { Variable } \\
\text { Dominant Eye }\end{array}$ & \multicolumn{3}{c|}{ Aiming Error (Mean \pm SD) } \\
\hline \multirow{3}{*}{$\begin{array}{l}\text { Golf Ball and Putter } \\
\text { Combination }\end{array}$} & One-Line Putter and One-Line Ball & $+072 \pm 2.64$ & $-0.14 \pm 2.16$ & 0.354 \\
\cline { 2 - 5 } & One-Line Putter and Three-Line Ball & $+1.81 \pm 1.20$ & $-0.08 \pm 1.89$ & $\mathbf{0 . 0 2 3}$ \\
\cline { 2 - 5 } & Three-Line Putter and One-Line Ball & $-0.60 \pm 2.36$ & $-2.40 \pm 2.14$ & $\mathbf{0 . 0 3 7}$ \\
\cline { 2 - 5 } & Three-Line Putter and Three-Line Ball & $+0.01 \pm 1.89$ & $-1.79 \pm 2.05$ & $\mathbf{0 . 0 1 6}$ \\
\hline
\end{tabular}

Abbreviations: SD, standard deviation; OD, right eye; OS, left eye; n, number. $P$-value $<0.05$ is shown in bold.

The relationship between visual function and alignment errors was investigated as the alignment error of balls according to eye dominance, alignment error of putters according to eye dominance (Table 5), alignment error of ball and putter combinations according to eye dominance (Table 6), and correlations of alignment error of balls/ putters with stereoacuity/fixation disparity. At both putting distances, all the subjects aimed to the left of the fixation point, and bias was greater for a dominant left eye (OS) than for a dominant right eye (OD); however, the difference was not statistically significant $(P>0.05)$ (Table 5$)$. For both putter types, there was a difference in the alignment error of the putter between a dominant OS and a dominant OD. The alignment error of the threeline putter was greater to the left for a dominant OS than for a dominant OD; however, the difference was not statistically significant (Table 5). All alignment errors were more biased to the direction of the dominant eye, and except for the combination of a one-line putter with a one-line ball, there were significant differences between dominant OD and OS eyes for all ball and putter combinations (all $P<0.05$ ) (Table 6).

In both stereopsis and fixation disparity, the combination of putting distance and a three-line ball showed 
negative correlations, while all other combinations showed positive correlations. However, the distance and near stereoacuity and fixation disparity were not significantly correlated with the alignment errors of the one- and threeline balls at putting distances of $1.5 \mathrm{~m}$ and $3 \mathrm{~m}$, or for one- and three-line putters when used with one- and three-line balls at a putting distance of $1.5 \mathrm{~m}$ (all $P>0.05)$.

Analysis of subjective satisfaction results using a questionnaire revealed that aiming lines on both the putter and golf ball was helpful for aligning in putting. Subjective satisfaction increased significantly with the increase in the number of aiming lines on golf balls and putters. The mean \pm SD of the final satisfaction score was significantly higher for the three-line ball $(2.53 \pm 0.59)$ than for the one-line ball $(1.63 \pm 0.58)$, and for the three-line putter $(2.74$ $\pm 0.49)$ than for the one-line putter $(1.70 \pm 0.74)$ (both $P<0.001)$.

\section{DISCUSSION}

Many previous studies evaluated the putting skills of expert golfers $[17,18]$. In the current study, to determine the subjects' average score, subjects who knew their typical number of strokes were selected, using the same method as in previous studies; subjects were asked to write this down before the experiment commenced [21].

As suggested by some previous studies, the alignment error of the putter head affects the movement direction of the golf ball following the stroke, and Park [18] suggested that, at a distance of $3 \mathrm{~m}$, the alignment error in the direction of the club head affects the address and impact. Accordingly, the current study assumed that the alignment error of the putter head would be the same as the movement direction of the golf ball, and our results agreed with these previous studies.

According to Woo [9], success in putting is not related to the gaze processing direction and is greater in experts than in beginner golfers. However, the current study did not find any significant difference in alignment accuracy between the expert and beginner golfers groups, and found some conflicting results. These conflicting findings may be due to the classification of subjects who had an average score lower than 90, although having golf experience, in the beginner golfers group, whereas previous studies selected subjects without any golf experience as beginner golfers [9].

Since this study predicted that an aiming line would be more helpful to beginner golfers, golfers were divided into beginners and experts. Unlike many previous studies to date, this study classified beginner and expert golfer groups based on subjects' golf experience. The success rate of a golf game depends on many golfer-related variables, such as the power of exercise, quickness, concentration, and mental power. However, finally, it has a single goal of transferring the golf ball into the hole cup by putting $[10,22]$. Thus, the predicted putting success rate used as an outcome in this study focused on the original purpose of the golf game. However, in order to analyze the effect on more accurate golf putting, it is necessary to include the kinematic and mental aspects of golfers in follow-up studies.

In the current study, the distance and near stereoacuity and fixation disparity did not correlate significantly with alignment errors of one-line or three-line golf balls at putting distances of $1.5 \mathrm{~m}$ and $3 \mathrm{~m}$. Likewise, the distance and near fixation disparity did not correlate significantly with the alignment error of the one-line and three-line putters when using one- and three-line balls at a putting distance of $1.5 \mathrm{~m}$. Lohmeyer et al. reported that stable or unstable fixation disparity, or fixation disparity greater or less than $3 \mathrm{arcmin}$ had no significant effect on golfers' subjective putting abilities [17].

In the current study the presence and number of aiming lines on golf balls and putters and golf experience were not related with the accuracy of golf ball alignment. However, the accuracy of the putter alignment increased significantly for the three-line putter as compared to the one-line putter. The predicted putting success rate and subjective satisfaction were increased when three-line golf balls and putters were used, as compared to when one-line golf balls and putters were used. The alignment error was greater to the left for a dominant OS than for a dominant OD.

As a limitation, the questionnaire used in this study was developed based on the author's background knowledge, and its validity and reliability were not assessed. Therefore, for future use, it is recommended that the validity and reliability of the questionnaire first be verified. Future studies should investigate kinematic aspects and visual function, which may provide a more insightful understanding of the effect of the presence and number of aiming lines on alignment in putting.

\section{CONCLUSIONS}

The accuracy of the golf ball alignment was not affected by the number of aiming lines on the golf ball and career. Nevertheless, the predicted putting success rate and subjective satisfaction were increased when three-line golf balls and putters were used, as compared to when one-line golf balls and putters were used. The alignment of golf 
balls and putters is part of the putting process. To analyze the impact of aiming lines on alignment errors more clearly, it is necessary to conduct a follow-up study including kinematic aspects and visual function.

\section{ETHICAL DECLARATIONS}

Ethical approval: This study was approved by the institutional review board of Eulji University, Korea (Approval No.: EU20-07), and subjects consented to participation after receiving an explanation of the purpose and details of the study.

\section{Conflict of interests: None.}

\section{FUNDING}

\section{None.}

\section{ACIKNOWLED GEMENTS}

This study was published in a local language journal, the Korean Journal of Vision Science (https:// db.koreascholar.com/article? code $=\mathbf{4 0 4 2 5 3}$ ). The former journal granted us the copyright to publish this study in the Medical Hypothesis, Discovery \& Innovation in Optometry Journal in English for wider audiences. We also thank Callaway Korea Co. for providing souvenirs to the participants.

\section{REFERENCES}

1. Pelz D, James A, (2000). Dave Pelz's putting bible: The complete guide to mastering the green (pp. 1-101). New York, Doubleday. Available at: http://www.raymondstoop.nl/wp-content/uploads/2011/12/putting-bible.PDF (Accessed: February 10, 2021).

2. Har DH, Cho DH. The Kinematic analysis of change of putter head on putting accuracy. The Korean Journal of Physical Education. 2015;54(6):617-24.

3. Lee M-Y, Lee H-J. Analysis of inclination of amateur golfer putting stroke face angle and club path. Korean Journal of Sports Science. 2019;28(2):1121-7. doi: 10.35159/kjss.2019.04.28.2.1121

4. Yoo CK, Shin DJ, Park BY. Research on Psychological Factors of Golf Players on Experience Using Color Golf Balls. Journal of Sport and Leisure Studies. 2014;57(1):593-602. doi: 10.51979/kssls.2014.08.57.593

5. Dalton K, Guillon M, Naroo SA. Ocular Dominance and Handedness in Golf Putting. Optom Vis Sci. 2015;92(10):968-75. doi: 10.1097/OPX.0000000000000690 pmid: 26398349

6. Seong PJ, (2012). Introduction to optometry (3rd edition pp. 219-221). Seoul, Daihak Seorim Co. Ltd.

7. Kim SJ. The study of eye movement patterns in the golf putting task. Korean Journal of Sport Psychology. 2000;11(2):1-14.

8. Kim SH. Effects of Distance and Accuracy on Visual Search in Golf Putting. The Korean Journal of Sports Medicine. 2013;31(2):69-77. doi: $10.5763 / \mathrm{kjsm} .2013 .31 .2 .69$

9. Woo B-H, Kim C-W, Park Y-S, Lee K-C, Lim Y-T. The Effects of Accuracy on Skill Level and Eye-Tracking Type in Golf Putting. Korean Journal of Sport Biomechanics. 2009;19(4):729-38. doi: 10.5103/kjsb.2009.19.4.729

10. Dalton KN. (2013). 'The vision strategy of golf putting (Thesis)'. Birmingham, Aston University. Available at: https://publications. aston.ac.uk/id/eprint/19543/1/Studentthesis-2013.pdf (Accessed: February 10, 2021).

11. Won CH, (1994). 'Effect of visual alignment state on putting motion in golf game (Thesis)'. Seoul, Kookmin University. Available at: https://academic.naver.com/article.naver?doc id=9072739 (Accessed: February 10, 2021).

12. Bulson RC, Ciuffreda KJ, Hung GK. The effect of retinal defocus on golf putting. Ophthalmic Physiol Opt. 2008;28(4):334-44. doi: 10.1111/j.1475-1313.2008.00575.x pmid: 18565089

13. Faul F, Erdfelder E, Lang AG, Buchner A. G*Power 3: a flexible statistical power analysis program for the social, behavioral, and biomedical sciences. Behav Res Methods. 2007;39(2):175-91. doi: 10.3758/bf03193146 pmid: 17695343

14. Faul F, Erdfelder E, Buchner A, Lang AG. Statistical power analyses using G*Power 3.1: tests for correlation and regression analyses. Behav Res Methods. 2009;41(4):1149-60. doi: 10.3758/BRM.41.4.1149 pmid: 19897823

15. Bingham DR, Swartz TB. Equitable Handicapping in Golf. The American Statistician. 2000;54(3):170-7. doi: $10.1080 / 00031305.2000 .10474541$

16. Welch DA. 'Putting practice kit and method. US patent, 6872150, 2005. Available at: https://patents.google.com/patent/ US6872150B2/en?oq=USA+patent+6872150 (Accessed: February 10, 2021).

17. Lohmeyer N, Patel A, Thompson T, (2002). 'Fixation disparity instability and golf putting consistency (Thesis)'. College of Optometry. 1404. Doctoral dissertation, Oregon, Pacific University. Available at: https://core.ac.uk/download/pdf/212801461.pdf (Accessed: February 10, 2021).

18. Park J. A kinematic analysis for putter's in putting stroke. Korean Journal of Sport Biomechanics. 2001;11(2):319-31. Link

19. Konjevoda S, Striber N, Čanović S, Didović Pavičić A, (2019). Ophthalmologic Examination of the Child. In Eye Motility 2019 Jan 26, Edited by Ivana Mravicic, IntechOpen, . doi: 10.5772/intechopen.82338. Available at: https://www.intechopen.com/books/eye-motility/ophthalmologic-examination-of-the-child (Accessed: February 10, 2021).

20. Alanazi MA. Reproducibility of the Dunlop Test for Motor Ocular Dominance Stability Among Young Saudi Females. The Medical Journal of Cairo University. 2020;88(2):513-9. doi: 10.21608/mjcu.2020.104601

21. Shim J, Miller G, Lutz R. Use of Ball Line as an Alignment Aid in Putting. International Journal of Golf Science. 2012;1(2):71-80. doi: 10.1123/ijgs.1.2.71

22. Johnston A, Benton CP, Nishida S. Golfers may have to overcome a persistent visuospatial illusion. Perception. 2003;32(9):1151-4. doi: $10.1068 / \mathrm{p} 5056$ pmid: 14651327 